\title{
Improving the Transient Stability of the Mixed AC/DC Networks with FACTS
}

\author{
Ayachi Bilel, Ahcene Boukadoum, Salah Leulmi, Tahar Boukra
}

Department of Electrical Engineering, LES laboratory, University of Skikda, Algeria

\begin{tabular}{l}
\hline Article Info \\
\hline Article history: \\
Received May 9, 2018 \\
Revised Sep 6, 2018 \\
Accepted Dec 20, 2018 \\
\hline Keyword: \\
FACTS \\
HVDC \\
PF \\
TCSC \\
Transient stability \\
\hline
\end{tabular}

\begin{abstract}
It is probable that future power transmission systems will contain more HVDC-VSC links (High Voltage Direct Current-Voltage Source Converter) leading to a growing complexity in the study of its problem and so do the transient stability problems which are yet to be determined. In this context, this paper presents an efficient method to resolve this problem. Its main objective consists of improving transient stability of the AC/DC (Alternating Current/ Direct Current) power system network using FACTS (Flexible Alternating Current Transmission Systems). The overall performance of the FACTS was evaluated in an IEEE 14 bus test system by nonlinear simulations carried out using Matlab environment to check the performance of FACTS (TCSC, Thyristor Controlled Series Capacitor). The obtained results showed the effectiveness and robustness of FACTS in improving the transient stability of the systemt.
\end{abstract}

Copyright (C) 2018 Institute of Advanced Engineering and Science. All rights reserved.

\section{Corresponding Author:}

Ayachi Bilel,

Department of Electrical Engineering,

National Chung Cheng LES laboratory,

University 20 Aout 1955- Skikda, Algeria.

Email: ay_bilel@yahoo.fr

\section{INTRODUCTION}

Power system stability is one of the celebrated difficulties in power systems from 1920s [1]. Generally, transient instability has been the dominant stability problem in power systems, and has been the focus of much of the industry's attention about system stability [1]. Hence, transient stability (TS) has one of the best essential problems in power systems.

Historically, transient stability has attracted many attentions [2], as the loss of the stability can lead to tragic and economic consequences. In current day, power systems are facing a lot of challenges in expressions of system operation closer stability limits [3]. Due to the deregulation of power markets, power systems are disposed to work nearer to stability limits [3].

The important condition for secure operation of the systems is to keep the rotor angle deviation for all generators within acceptable limits after credible incidents [4]. A number of methods have been proposed, e.g. transient stability as nonlinear problem using differential and algebraic equations advanced by Kundur [5], Sauer and Pai [6]. Gan et al [7] transformed the swing equations from differential and algebraic equations to numerically algebraic equations and then united them to the standard PF (Power Flow) problem.

Transmission networks of modern power systems have been causing problems because of growing demand and restrictions on building new lines. One of the consequences of such a system is the threat of losing stability following a disturbance. In order to expand or enhance the power transfer capability of existing transmission network the concepts of FACTS is developed by the Electric Power Research Institute (EPRI) in the late 1980s. The main objective of FACTS devices is to replace the existing slow acting mechanical controls required to react to the changing system conditions by rather fast acting electronic controls [8]. 
Since its existence, the power system was produced, transported and distributed in AC [9]. But, in the last few years, the incorporation of subsets of transmission HVDC in AC transmission networks brought a significant change in the transport of the electric power [9]-[13].

In situation where the power system is subject to fault which may leads to lose its stability, clearing such fault in the adequate time is crucial to maintain the system stability. If the fault is cleared after the critical clearing time (CCT), the system stability is lost pushing the system in unstable region. The so-called critical clearing time (CCT) is therefore determined to tune our compensation apparatus.

The region of attraction in such a situation can be increased by using various controllers (FACTS), the TCSC is the best solution which provides necessary series compensation to regain synchronization and to reschedule power flows.

The rest of this paper is organised as follows, the transient stability problem and power system modeling is expressed Section 2. Methodology is described in Section 3. Experimental results are presented in Section 4; the conclusions are provided in Section 5.

\section{POWER SYSTEM COMPONENTS MODELING}

The main phase in a stability study is to create a mathematical model of the network during the transient. The elements included in the model are those affecting the acceleration (or deceleration) of the machine rotors. The complexity of the model depends upon the type of transient and system being investigated. Generally, the components of the power system that influence the electrical and mechanical torques of the machines should be included in the model, these components are elaborated in following subsections [5].

\subsection{Synchronous generators}

The transient stability problem in power system is defined by a differential algebraic equation, which can be resolute by time domain simulation. The swing equation for ith generators is [5], [14]-[17]:

$$
\begin{aligned}
& \frac{d \omega_{i}}{d t}=\frac{\omega_{i}}{M_{i}}\left[\left(P_{m i}-P_{e i}\right)-D\left(\omega_{s}-\omega_{i}\right)\right] \\
& \frac{d \delta_{i}}{d t}=\omega_{i}-\omega_{s} \quad \text { where } \quad i=1, \ldots \ldots, n_{g} \\
& \frac{d E_{d i}^{\prime}}{d t}=\frac{1}{T_{q i 0}^{\prime}}\left[-E_{d i}^{\prime}+\left(X_{q i}-X_{q i}^{\prime}\right) i_{q i}\right] \\
& \frac{d E_{q i}^{\prime}}{d t}=\frac{1}{T_{d i 0}^{\prime}}\left[E_{f d i}-E_{q i}^{\prime}-\left(X_{d i}-X_{d i}^{\prime}\right) i_{d i}\right] \\
& \frac{d E_{f d i}}{d t}=\frac{1}{T_{A i}}\left[-E_{f d i}+K_{A i}\left(V_{r e f i}-V_{t}\right)\right]
\end{aligned}
$$

Where: $\delta_{i}$ is rotor angle of ith generator; $\omega_{i}$ is rotor speed of ith generator; $D$ is damping constant factor of ith generator; $P_{m i}$ is mechanical input power of ith generator; $P_{e i}$ is electrical output power of ith generator; $P_{e i}$ is electrical output power of ith generator; $M_{i}$ is moment of inertia of ith generator; $n_{g}$ is number of generator; $E_{d i}^{\prime}$ and $E_{q i}^{\prime}$ are the internal transient voltage of ith generator; $E_{f d i}$ is the excitation voltage of ith generator; $i_{d i}$ and $i_{q i}$ are the d-axis and q-axis courant of ith generator; $T_{d i 0}^{\prime}$ and $T_{q i 0}^{\prime}$ are the dopen circuit and q-open circuit transient time constants of ith generator; $X_{d i}^{\prime}$ and $X_{q i}^{\prime}$ are the d-transient reactance and q-transient reactance of ith generator; $X_{d i}$ and $X_{q i}$ are the d-synchronous reactance and qsynchronous reactance of ith generator; $K_{A i}$ and $T_{A i}$ are the system excitation gain and time constant of ith generator; $V_{r e f i}$ is the voltage reference of ith generator; $V_{t}$ is the terminal voltage magnitude, the parameters as shown in Table 1. 
Table 1. IEEE-14 bus modified test system machine DATA

\begin{tabular}{|c|c|c|c|c|}
\hline Type & GENROU & GENROU & GENROU & GENROU \\
\hline Operation & Sync. Gen. & Sync. Gen. & Condenser & Condenser \\
\hline $\begin{array}{l}\text { Default Unit no } \\
\text { (New Unit no) }\end{array}$ & $1(15)$ & $2(16)$ & $3(17)$ & $6(19), 8(18)$ \\
\hline Rated power (MVA) & 448 & 100 & 40 & 25 \\
\hline Rated voltage (KV) & 22.00 & 13.80 & 13.80 & 13.80 \\
\hline $\mathrm{H}(\mathrm{s})$ & 0.85 & 0.80 & 0.00 & 0.00 \\
\hline Rated pf & 2.656 & 4.985 & 1.520 & 1.200 \\
\hline $\mathrm{D}$ & 2.000 & 2.000 & 0.000 & 0.000 \\
\hline $\mathrm{r}_{\mathrm{a}}(\mathrm{pu})$ & 0.0043 & 0.0035 & 0.000 & 0.0025 \\
\hline $\mathrm{X}_{\mathrm{d}}(\mathrm{pu})$ & 1.670 & 1.180 & 2.373 & 1.769 \\
\hline $\mathrm{X}_{\mathrm{q}}(\mathrm{pu})$ & 1.600 & 1.050 & 1.172 & 0.855 \\
\hline $\mathrm{X}_{\mathrm{d}}^{\prime}(\mathrm{pu})$ & 0.265 & 0.220 & 0.343 & 0.304 \\
\hline $\mathrm{X}_{\mathrm{q}}^{\prime}(\mathrm{pu})$ & 0.460 & 0.380 & 1.172 & 0.5795 \\
\hline $\mathrm{X},{ }_{\mathrm{d}}(\mathrm{pu})$ & 0.205 & 0.145 & 0.231 & 0.2035 \\
\hline$X,{ }^{\prime}(p u)$ & 0.205 & 0.145 & 0.231 & 0.2035 \\
\hline $\mathrm{X}_{\mathrm{L}}$ or $\mathrm{X}_{\mathrm{p}}(\mathrm{pu})$ & 0.150 & 0.075 & 0.132 & 0.1045 \\
\hline $\mathrm{X}_{\mathrm{d} 0}^{\prime}(\mathrm{s})$ & 0.5871 & 1.100 & 11.600 & 8.000 \\
\hline$X^{\prime}{ }^{\prime} 0(s)$ & 0.1351 & 0.1086 & 0.159 & 0.008 \\
\hline $\mathrm{X}^{\prime \prime}{ }_{\mathrm{d} 0}(\mathrm{~s})$ & 0.0248 & 0.0277 & 0.058 & 0.0525 \\
\hline $\mathrm{X}^{\prime \prime}{ }_{\mathrm{d} 0}(\mathrm{~s})$ & 0.0267 & 0.0351 & 0.201 & 0.0151 \\
\hline$S(1.0)$ & 0.091 & 0.0933 & 0.295 & 0.304 \\
\hline $\mathrm{S}(2.0)$ & 0.400 & 0.4044 & 0.776 & 0.666 \\
\hline
\end{tabular}

\subsection{Basic governor control system}

Governor control system controls the speed and power output of the hydroelectric turbine, water level controlled power output controllers can be used for grid connected units. The block diagram of Figure 1 shows a typical governor for a hydraulic turbine

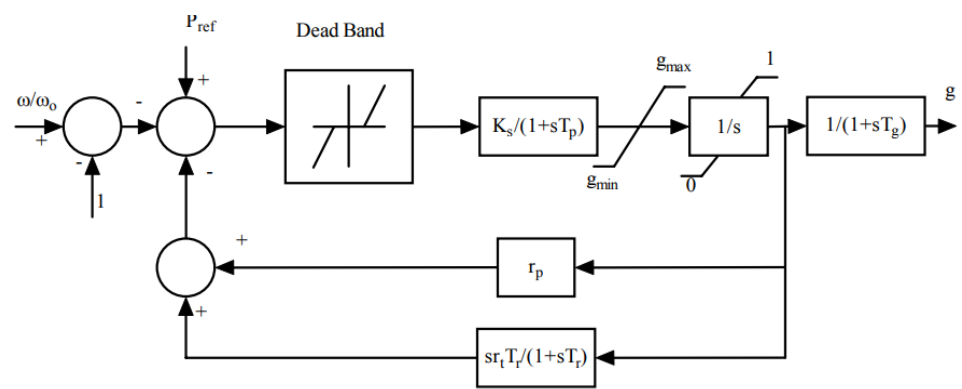

Figure 1. Block diagram of governor control system

Where $r_{t}$ is the temporary droop; $T_{r}$ is the reset time; $K_{s}$ gate servo gain; $T_{P}$ pilot servo time constant; $T_{g}$ gate power servo time constant; $g_{\max }$ and $g_{\min }$ are the maximum and minimum rate of change of gate position; $g$ gate position, the parameters as shown in Table 2.

Table 2. IEEE-14 bus modified test system governor DATA

\begin{tabular}{ccc}
\hline Type & IEEET1 & IEEET1 \\
\hline Operation & BPA_GG & BPA_GG \\
Default Unit no & $1(15)$ & $2(16)$ \\
(New Unit no) & 448 & 100 \\
Rated power (MVA) & 22 & 13.8 \\
Rated voltage (KV) & 0.870 & 1.050 \\
$\mathrm{P}_{\max }(\mathrm{pu})$ & 0.011 & 0.050 \\
$\mathrm{R}(\mathrm{pu})$ & 0.100 & 0.090 \\
$\mathrm{~T}_{1}(\mathrm{~s})$ & 0.000 & 0.000 \\
$\mathrm{~T}_{2}(\mathrm{~s})$ & 0.300 & 0.200 \\
$\mathrm{~T}_{3}(\mathrm{~s})$ & 0.050 & 0.300 \\
$\mathrm{~T}_{4}(\mathrm{~s})$ & 10.00 & 0.000 \\
$\mathrm{~T}_{5}(\mathrm{~s})$ & 0.250 & 1.000 \\
$\mathrm{~F}$ &
\end{tabular}




\subsection{Excitation}

There are a number of types of excitation system which all have the same aim. We consider here as shown in Figure 2, and the corresponding parameters are shown in Table 3.

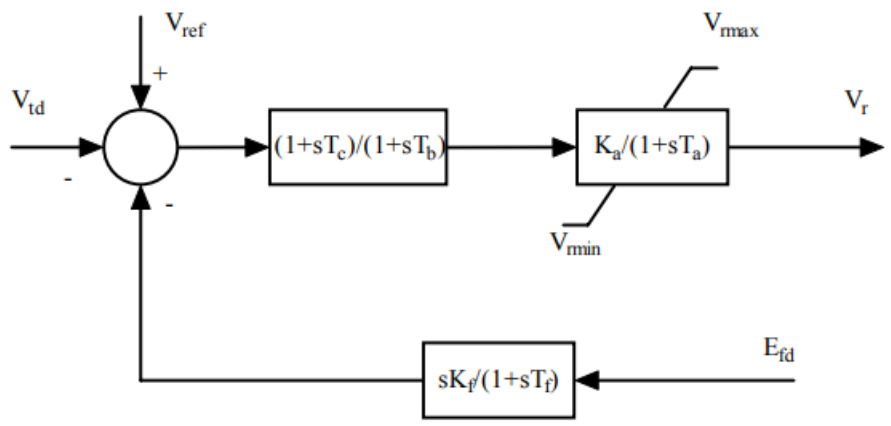

Figure 2. Block diagram of excitation

Where $K_{a}$ is the voltage regulator gain; $T_{a}, T_{b}$ and $T_{c}$ are the regulator time constant; $K_{f}$ is the rate feedback gain; $T_{f}$ is the rate feedback time constant; $V_{\max }$ and $V_{\min }$ are the maximum and minimum voltage regulator output.

Table 3. IEEE-14 bus modified test system exciter DATA

\begin{tabular}{ccccc}
\hline Type & IEEET1 & IEEET1 & IEEET1 & IEEET1 \\
\hline Operation & Sync. Gen. & Sync. Gen. & Condenser & Condenser \\
Default Unit no & $1(15)$ & $2(16)$ & $3(17)$ & $6(19), 8(18)$ \\
(New Unit no) & & 100 & 40 & 25 \\
Rated power $(\mathrm{MVA})$ & 448 & 13.80 & 13.80 & 13.80 \\
Rated voltage $(\mathrm{KV})$ & 22.00 & 0.060 & 0.00 & 0.00 \\
$\mathrm{~T}_{\mathrm{r}}(\mathrm{s})$ & 0.000 & 25 & 400 & 400 \\
$\mathrm{k}_{\mathrm{a}}(\mathrm{pu})$ & 50 & 0.200 & 0.050 & 0.050 \\
$\mathrm{~T}_{\mathrm{a}}(\mathrm{s})$ & 0.060 & 1.000 & 6.630 & 4.407 \\
$\mathrm{~V}_{\mathrm{Rmax}}(\mathrm{pu})$ & 1.000 & -1.000 & -6.630 & -4.407 \\
$\mathrm{~V}_{\mathrm{Rmin}}(\mathrm{pu})$ & -1.000 & -0.0582 & -0.170 & -0.170 \\
$\mathrm{k}_{\mathrm{e}}(\mathrm{pu})$ & -0.0465 & 0.6544 & 0.950 & 0.950 \\
$\mathrm{~T}_{\mathrm{e}}(\mathrm{s})$ & 0.520 & 0.105 & 0.040 & 0.040 \\
$\mathrm{k}_{\mathrm{f}}(\mathrm{pu})$ & 0.0832 & 0.350 & 1.000 & 1.000 \\
$\mathrm{~T}_{\mathrm{f}}(\mathrm{s})$ & 1.000 & 2.5785 & 6.375 & 4.2375 \\
$\mathrm{E}_{1}(\mathrm{pu})$ & 3.240 & 0.0889 & 0.2174 & 0.2174 \\
$\left.\mathrm{SE}_{(\mathrm{E}}\right)$ & 0.072 & 3.438 & 8.500 & 5.650 \\
$\mathrm{E}_{2}(\mathrm{pu})$ & 4.320 & 0.3468 & 0.9388 & 0.9386 \\
$\mathrm{SE}\left(\mathrm{E}_{2}\right)$ & 0.2821 & & &
\end{tabular}

\subsection{Power system stabilizer}

The power system stabilizer (PSS) is a device that measures improvements in system stability when added to a generator's automatic voltage regulator (AVR), as shown in Figure 3.

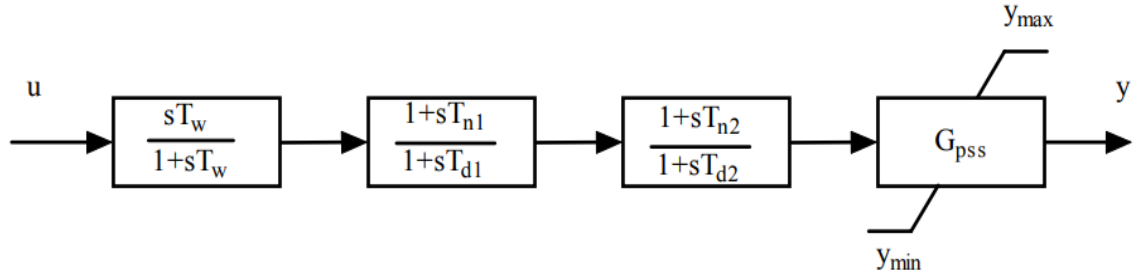

Figure 3. Block diagram of power System Stabilizer 
Where $T_{W}$ is washout time constant; $T_{n 1}$ and $T_{n 2}$ are the first and second lead times constant; $T_{d 1}$ and $T_{d 2}$ are the first and second lag time constant; $y_{\max }$ and $y_{\min }$ are the PSS maximum and minimum output limits; $G_{P S S}$ is PSS gain.

\subsection{Transmission lines}

The transmission lines are characterized by the equivalent $\pi$ model.

\subsection{Transformers}

Generally, there are three types of transformers; two-winding, three-winding transformers and the phase shifting transformer. Here we consider first and second.

\subsection{Loads}

Constant admittance power loads are modeled as a specified quantity of real and reactive power disbursed at its bus i.

$$
Y_{l}(i)=G_{l}(i)+j B_{l}(i)=\frac{P_{l}(i)+j Q_{l}(i)}{V_{k}^{2}(i)}
$$

where $P_{l}(i)$ and $Q_{l}(i)$ are the active and reactive power at bus $i ; V$ voltage magnitude at bus $i$.

\subsection{FACTS}

a. $S V C$

The Static VAR Compensator (SVC), is a member of the FACTS family that is connected in shunt with $\mathrm{AC}$ power systems, as shown in Figure 4 and the parameters as shown in Table 4 . The goal functionality is to regulate the voltage at a specified bus by controlling its equivalent reactance.

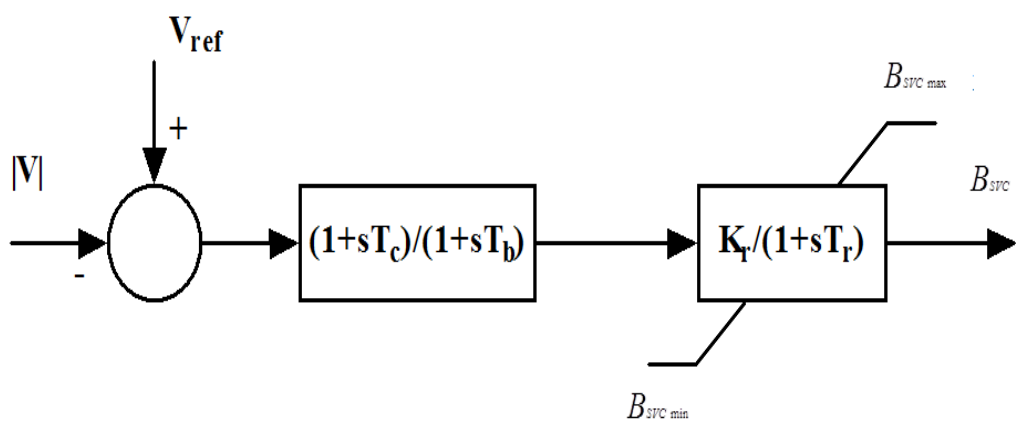

Figure 4. Block diagram of SVC

Where $T_{c}$ and $T_{b}$ are the leads and lag times constant; $T_{r}$ is regulator time constant; $K_{r}$ is regulator gain, $B_{S V C \max }$ and $B_{S V C \min }$ are maximum and minimum output suscetance;

Table 4. IEEE-14 bus modified test system SVC DATA

\begin{tabular}{cccccc}
\hline $\mathrm{B}_{\mathrm{cmax}}(\mathrm{pu})$ & $\mathrm{B}_{\mathrm{cmin}}(\mathrm{pu})$ & $\mathrm{K}_{\mathrm{r}}(\mathrm{pu})$ & $\mathrm{T}_{\mathrm{r}}(\mathrm{s})$ & $\mathrm{T}_{\mathrm{c}}(\mathrm{s})$ & $\mathrm{T}_{\mathrm{b}}(\mathrm{s})$ \\
\hline 5 & -5 & 10 & 0.02 & 0 & 0 \\
\hline
\end{tabular}

\section{b. TCSC}

TCSC can be seen as a controllable reactance inserted in the related transmission line. TCSC works by reducing the effective series impedance of the transmission line; hence the power transferred is increased, as shown in Figure 4. 


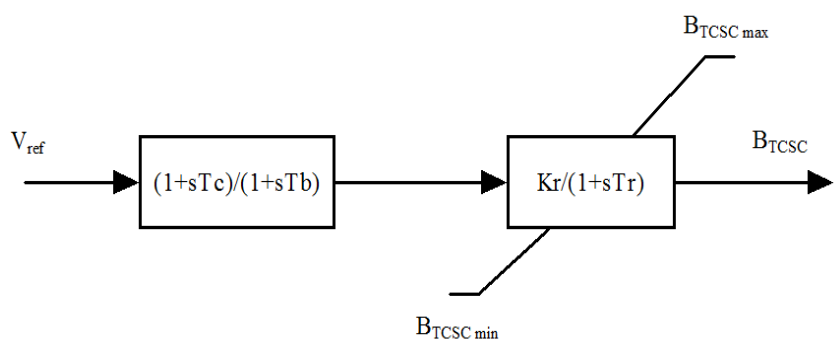

Figure 5. Block diagram TCSC

Where $T_{c}$ and $T_{b}$ are the leads and lag times constant; $T_{r}$ is regulator time constant; $K_{r}$ is regulator gain, $B_{T C S C \max }$ and $B_{T C S C \text { min }}$ are maximum and minimum output suscetance; as shown in Table 5.

Table 5. IEEE-14 bus modified test system TCSC DATA

\begin{tabular}{llllll}
\hline $\mathrm{B}_{\text {cmax }}(\mathrm{pu})$ & $\mathrm{B}_{\mathrm{cmin}}(\mathrm{pu})$ & $\mathrm{K}_{\mathrm{r}}(\mathrm{pu})$ & $\mathrm{T}_{\mathrm{r}}(\mathrm{s})$ & $\mathrm{T}_{\mathrm{c}}(\mathrm{s})$ & $\mathrm{T}_{\mathrm{b}}(\mathrm{s})$ \\
\hline 8.2 & 0 & 1 & 0.05 & 0 & 0 \\
\hline
\end{tabular}

\subsection{HVDC-VSC}

The HVDC-VSC comprises two VSCs: One operating as a rectifier and the other as an inverter. The two converters are linked either back-to-back by a DC transmission. One VSC controls DC voltage and the other acts on the active power transmission through the DC link [18].

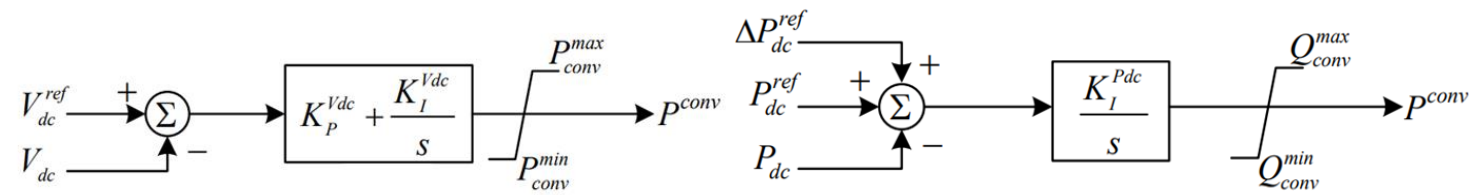

Figure 6. Block diagram of HVDC-VSC injection model controller DC voltage and active power

where $K$ is gain; $P_{c o n v}^{\max }, P_{c o n v}^{\min }, Q_{c o n v}^{\operatorname{mx}}, Q_{c o n v}^{\min }$ are the maximum and minimum limits of active and reactive power of the HVDC converter; $P^{c o n v}$ is the active power injections to the AC network; $V_{d c}$ is DC voltage; $P_{d c}$ is DC active power injection; as shown in Table 6.

Table 6. IEEE-14 bus modified test system HVDC DATA

\begin{tabular}{lllll}
\hline $\mathrm{k}^{\mathrm{pdc}}{ }_{1}(\mathrm{pu})$ & $\mathrm{K}^{\mathrm{vdc}}{ }_{1}(\mathrm{pu})$ & $\mathrm{K}^{\mathrm{vdc}}{ }_{\mathrm{p}}(\mathrm{pu})$ & $\mathrm{U}_{\mathrm{dcmin}}(\mathrm{pu})$ & $\mathrm{U}_{\mathrm{dcmax}}(\mathrm{pu})$ \\
\hline 20 & 40 & 3 & 0.8 & 1.2 \\
\hline
\end{tabular}

\section{METHODOLOGY}

According to Section 2, a methodology was developed to find the CCT. The methodology began with the modeling of IEEE-14 bus system governed by (1)-(6) and the simulation of the block diagrams of Figures 4-6. A stability analysis was conducted for test fault situation of 3 phase fault near bus 1 (line 1-2). An appropriate fault clearing time was set for each stability analysis of the system and gradually increased till the system became unstable.

In this case, in order to maintain the transient stability, a TCSC was installed near bus 2 and in series with the transmission line between bus 2 and bus 5 . The maximum compensation by TCSC was limited to 70\% of the reactance of the uncompensated line where TCSC is located. 


\section{CASE STUDY AND DISCUSSIONS}

The IEEE 14-bus modified test system consisted of 5 synchronous machines with IEEE type-1 exciters, 3 of which were synchronous compensators used only for reactive power support. There were 19 buses, 17 transmission lines, 8 transformers and 11 constant impedance loads. The total load demand was 259 MW and 73.5 MVAr [19].

The IEEE 14-bus system has been modified to incorporate the HVDC-VSC link between buses 2-4 and SVC at bus 9. The results consist of 2 cases. Case 1 was to analyse the effect of a 3 -phase fault at line 12 near bus 1 (cleared by tripping line 1-2) of the mixed AC/DC network and Case 2 was the implementation of TCSC controller and analysis on the same system as shown in Figure 7.

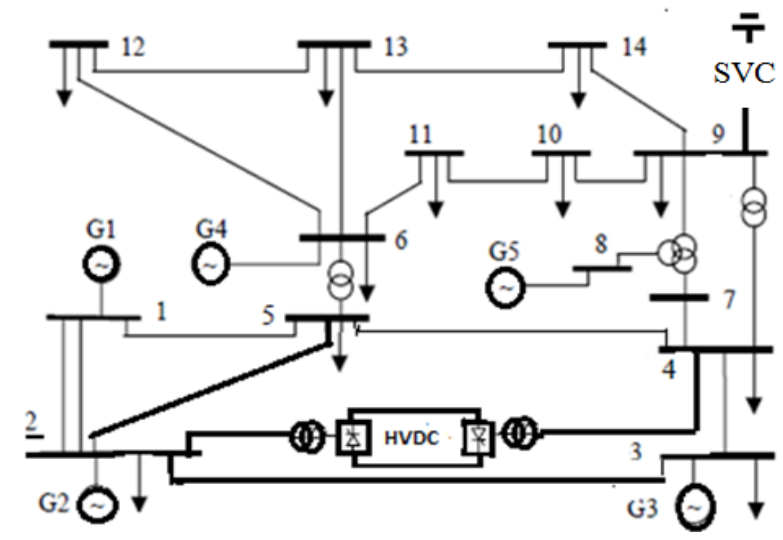

Figure 7. IEEE-14 bus test systems
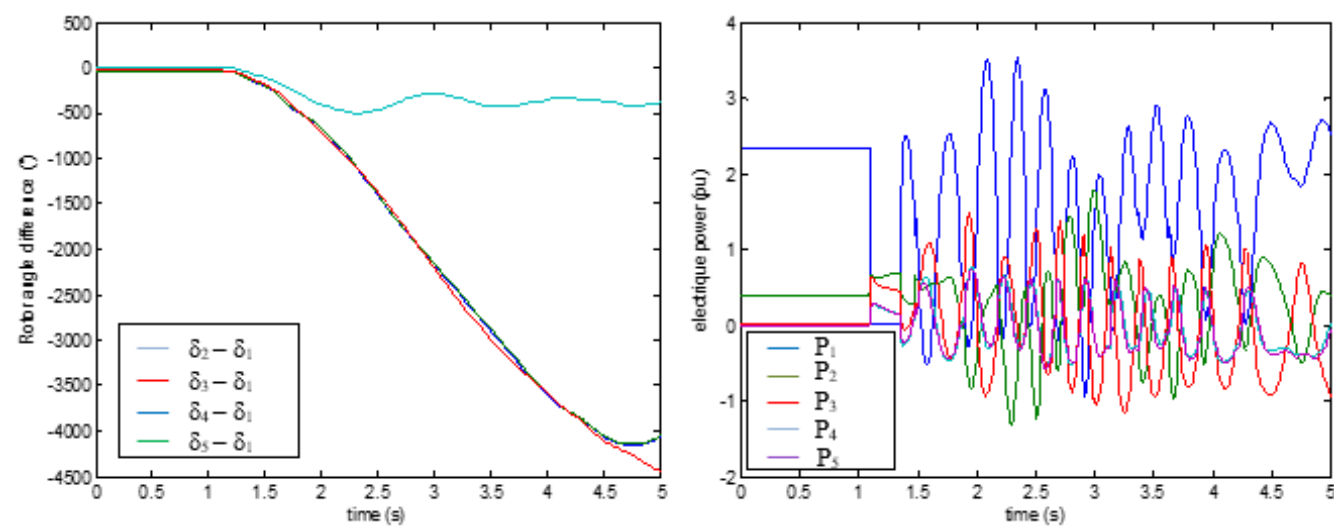

Figure 8. Unstable system response, clearing time tc $=0.29(\mathrm{~s})$.
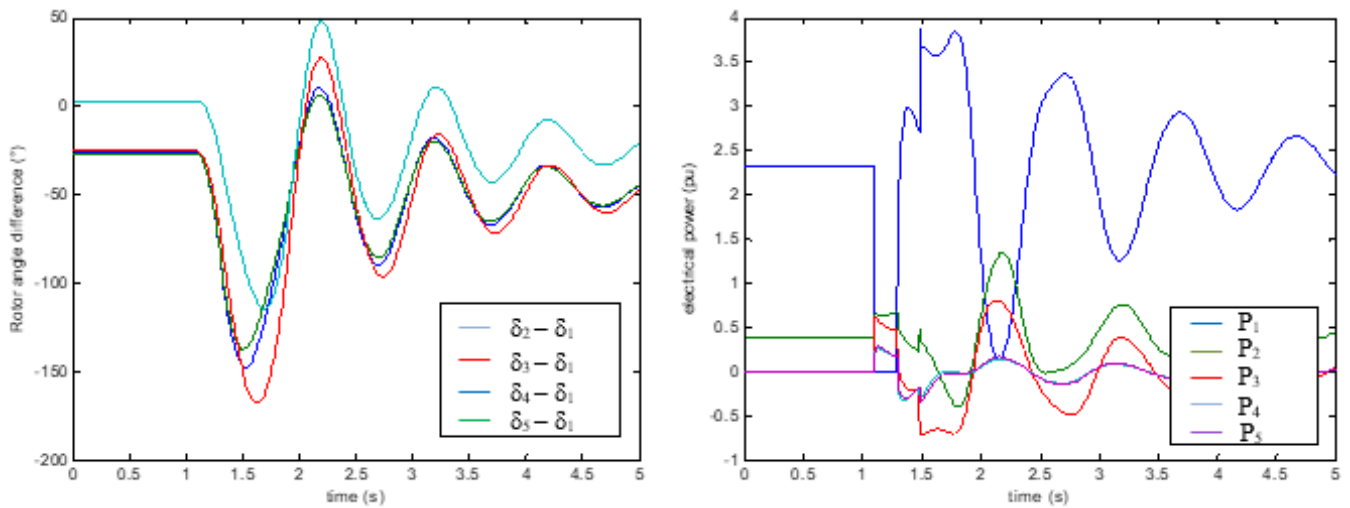

Figure 9. Stable system response, clearing time tc $=0.28(\mathrm{~s})$. 
For Case 1, Figure 8 and Figure 9 shows the response of the rotor angle and electrical power for two different values of clearing time. The system however becomes unstable when the clearing time is 0.29 (s) and stable when the clearing time is 0.28 (s). However, in Case 1, it was found that system transient stability was lost following the incident disturbance at line 1-2 near bus 1 . Visibly, the system cannot be operating in this mode because security of the network was violated.

In case 2, compared to the case 1, in order to maintain the transient stability, a TCSC is installed at bus 2 and in series with the transmission line between bus 2 and bus 5. The TCSC improves transient stability margins. The results in Figure 10 and Figure 11 demonstrate the aptitude of TCSC to enhance power system transient stability.

These simulation results demonstrate the effectiveness of TCSC into improving transient stability. Proper use of TCSC gives better results and ensures system transient stability following the incident.
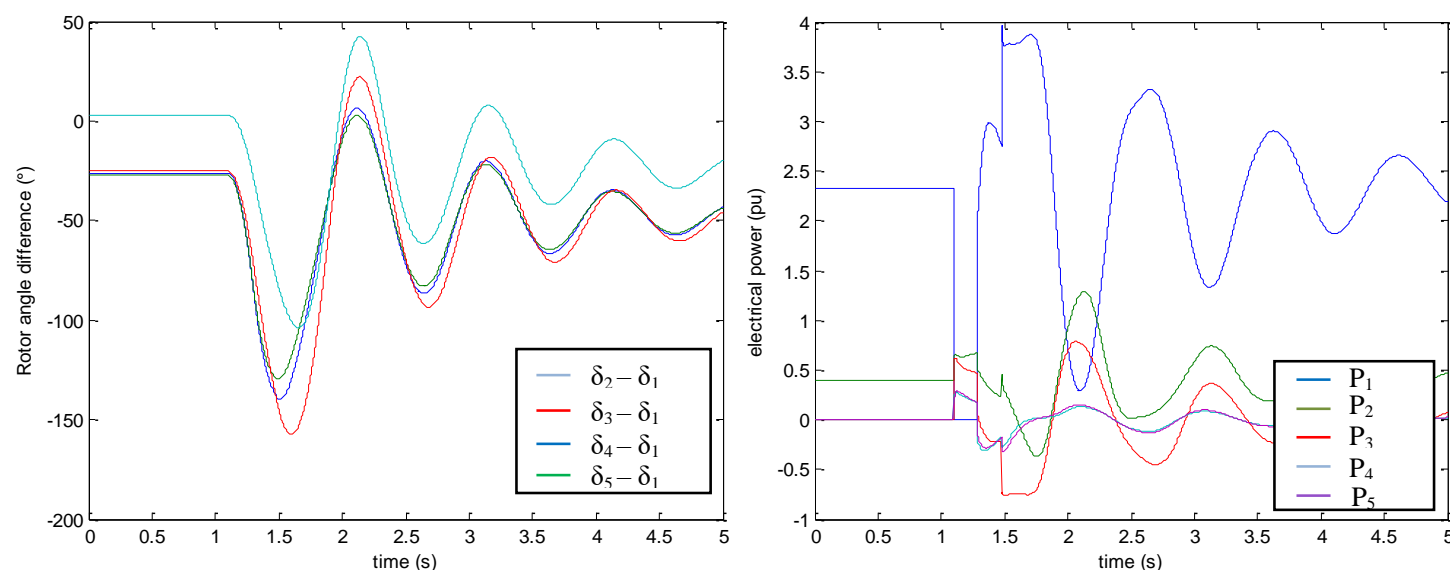

Figure 10. Stable system response, $\mathrm{tc}=0.29(\mathrm{~s})$ with TCSC connected at line 2-5.
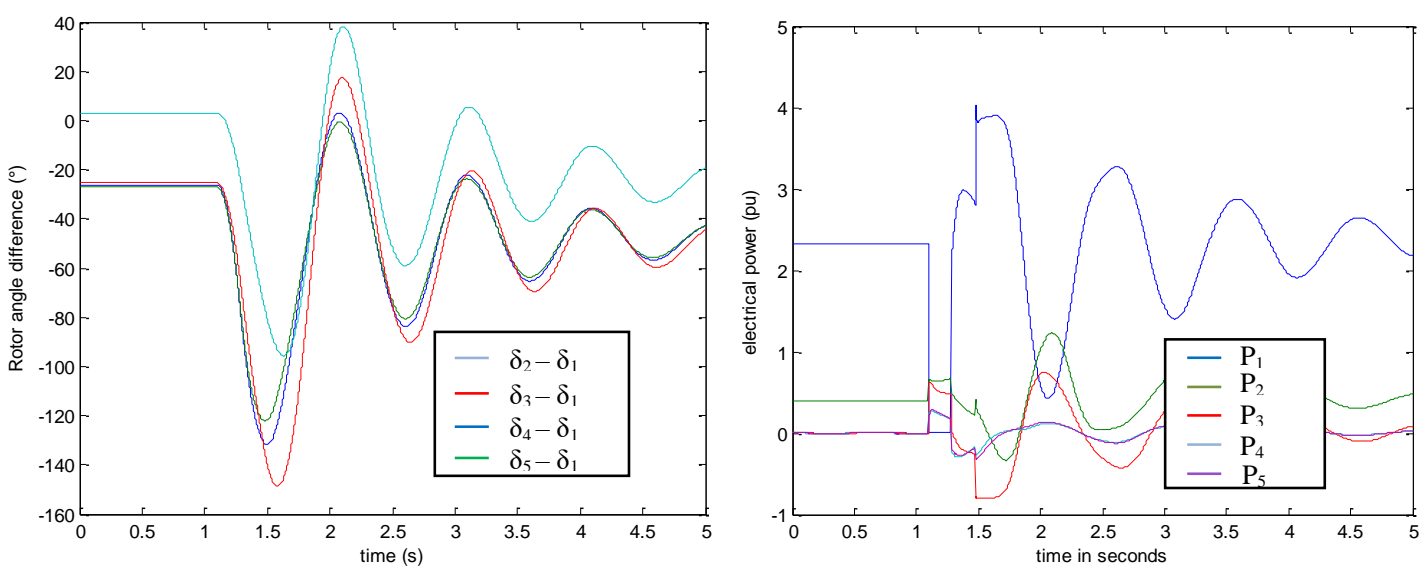

Figure 11. Stable system response's, tc $=0.28$ (s) with TCSC connected at line 2-5.

\section{COMPARISON TO PREVIOUS WORKS}

We have benchmarked our study to previous works like [20] which the authors have used the same power system (IEEE 14 bus) but without HDVC-VSC link. We have found a clear improvement concerning the CCT; up to $0.28 \mathrm{~s}$ instead of $0.145 \mathrm{~s}$ in [20].

Second comparison was made that emphasize the superiority of our method on the same power system without HDVC. In this case, the active losses are taken as a parameter of comparison. We have found 7.83 MW of active power losses in our proposal instead of 15.2 MW in [21]. 


\section{CONCLUSION}

This paper investigates the improvement of transient stability using TCSC which is an effective FACTS device capable of controlling the electrical power and rotor angle in a transmission link by governing its series parameters.

FACTS devices, such as TCSC can be very active in case of the incident. In this paper, we have focused on the improvement of the transient stability in presence of fault via the use of TCSC. The transient stability of the mixed AC/DC network is compared with and without the use of TCSC. The simulation results prove the efficiency of the integrated TCSC on transient stability improvement.

\section{REFERENCES}

[1] Kundur P, Paserba J, Ajjarapu V, Andersson G, Bose A, Canizares C, Hatziargyriou N, Hill D, Stankovic A, Taylor C, Van Cutsem T, Vittal V, "Definition and Classification of Power System Stability," IEEE Transactions on Power Systems, vol. 19(2), pp. 1387-1401, May 2004.

[2] Momoh J A, Koessler R J, Bond M S, et al, "Challenges to Optimal Power Flow," IEEE Transactions on Power Systems, vol. 12(1), pp. 444-455, 1997.

[3] ThanhLong D, Yao J G, VietAnh T, "Improving the Transient Stability-Constrained Optimal Power Flow with Thyristor Controlled Series Compensators," Russian Electrical Engineering. vol. 85(12), pp. 777-784, 2014.

[4] Zerigui A, Dessaint L A, Hannat R, Robert T F, Kamwa I, "Statistical Approach for Transient Stability Constrained Optimal Power Flow," IET Gener. Transm. Distrib. vol. 9(14), pp. 1856-1864, 2015.

[5] Kundur P. Balu N J \& Lauby M G., "Power System Stability and Control,” New York: McGraw-hill. 1994.

[6] Sauer P W, Pai M A. Wiley. "Power System Dynamics and Stability: With Synchrophasor Measurement and Power", Urbana. 1998.

[7] Gan D, Thomas R J, Zimmerman R D, "Stability-Constrained Optimal Power Flow," IEEE Transactions on Power Systems, vol. 15(2), pp. 535-540, May 2000.

[8] Manoz K, Kumar R, "Damping of Oscillations of Multi-machine Power Systems with Multiple UPFC," International Journal of Advanced Research in Computer Science and Software Engineering, vol. 2(5), pp. 267-271, 2012.

[9] Mezhoud N, Leulmi S, Boukadoum A, "AC-DC Optimal Power Flow Incorporating Shunt FACTS Devices Using HVDC Model and Particle Swarm Optimization Method," International Review Electrical Engineering, vol. 9(2), pp. 382-392, 2014.

[10] Sato H Arrillaga J, "Improved Load-Flow Techniques for Integrated AC/DC Systems," Institution of Electrical, vol. 116(4), pp. 525-532, 1969.

[11] Reeve J, Fahny G, Stott B, "Versatile Load Flow method for Multi-terminal HVDC Systems," IEEE Transactions on Power Apparatus and Systems, vol. 96(3), pp. 525-532, 1977.

[12] El-Marsafaw M M, Mathur RM, "A New Fast Technique for Load-Flow Solution of Integrated Multi-terminal DC/AC Systems," IEEE Transactions on Power Apparatus and Systems, vol. 99(1), pp. 246-255, 1980.

[13] Fudeh H, Ong C M, "A simple and Efficient AC-DC Load-Flow Method for Multi-terminal DC Systems," IEEE Transactions on Power Apparatus and Systems, vol. 100(11), pp. 4389-4396, 1981.

[14] Ayachi B, Boukadoum A, Leulmi S, "Improvement the Transient Stability with FACTS (UPFC)," International Conference on Electrical Networks ICEN'10, Algeria pp. 169-174, 2010.

[15] Krishna S, “An Introduction to Modelling of Power System Components,” Springer, 2014.

[16] Preece R, "A Probabilistic Approach to Improving the Stability of Meshed Power Networks with Embedded HVDC Lines," Doctor of Philosophy. University of Manchester, 2013

[17] Deqiang G, Thomas R G, Zimmerman R D. “A Transient Stability Constrained Optimal Power Flow," Bulk Power System Dynamics and Control-Restructuring. Greece, vol. 5. p.720, 1998.

[18] Acha E, Fuerte-Esquivel C R, Ambriz-Pérez H, Camacho C A. "FACTS Modelling and Simulation In Power Networks," Wiley, New York, 2004.

[19] http://www.kios.ucy.ac.cy/testsystems/index.php/dynamic-ieee-test-systems/ieee-14-bus-modified-test-system.

[20] Hashim N, Hamzah N, Abdul Latip M F, Sallehhudin A A, "Transient Stability Analysis of the IEEE 14-Bus Test System Using Dynamic Computation for Power Systems (DCPS) International Conference on Intelligent Systems Modelling and Simulation," IEEE Computer society, pp. 481-486, 2012.

[21] Demetriou P, Asprou M, Quiros T J, Kyriakides E, "Dynamic IEEE Test Systems for Transient Analysis," IEEE Systems Journal, vol. 11(04), pp. 2108-2117, 2017. 